\title{
Unrecognised informal solid waste recycling in an emerging African megacity: a study of Johannesburg, South Africa
}

\author{
S. Q. Dlamini \& D. Simatele \\ Archaeology and Environmental Studies, School of Geography, \\ University of the Witwatersrand, South Africa
}

\begin{abstract}
Informal solid waste recycling has increasingly become part of the urban landscape in many South African cities and towns. In the city of Johannesburg, for example, informal solid waste pickers are now playing an important role in the recycling of different types of waste. There is evidence in literature which suggests that these activities have both economic and environmental benefits contributing towards employment creation and environmental sustainability. Despite the role that the informal sector contributes to waste management and socioeconomic development, as well as environmental sustainability, the urban development and planning policy in South Africa have not embraced and integrated these activities in the policy framework. Drawing from a field-based study, conducted in selected parts of the city of Johannesburg, and using methods inspired by the traditional of participatory research, this paper explores the institutional framework within which informal solid waste management can be pursued. The paper is specifically interested in identifying and discussing contemporary challenges, mechanisms, systems and processes that may contribute towards the sustained neglect of the informal sector in the urban solid waste management and planning policy.

Keywords: informal solid waste collection, solid waste management, solid waste recycling, Johannesburg, South Africa.
\end{abstract}

\section{Introduction}

The informal solid waste recycling has emerged as a livelihood strategy of the low-income urban residents who have found themselves vulnerable and squeezed 
on the side-lines of the process of industrialisation. Unable to cope with the pressure of a capitalist system which is based on individualism and that of higher market demand and competitiveness, most of the urban poor residents of the developing world have resolved to informally operate in the sector of waste recycling for their survival. SAIRR [1] and supported by the World Bank survey, for example, makes reference to higher demographic pressure observed in the cities of the developing world which has created a situation that the urban authorities cannot be able to meet the needs and aspirations of their residents in terms of employment. The disadvantaged and marginalised group of people in society have to adapt to the pressure of the capitalist system and have to come up with their own means of survival among which include informal solid waste recycling in cities.

In South Africa, for example, two-thirds of the population lives in urban areas (SAIRR [1]). This situation is apparently the result of the rural exodus phenomenon through which people migrate from the rural areas to the towns and cities in search of job opportunities and the so-called 'good life'. It can also be argued that the demographic pressure has created an enormous pressure upon the local municipal authorities who have proved to be unable to provide adequate and equitable solid waste management service to the various segments of the population dwelling in their respective jurisdictions (Kubanza and Simatele [2]). Karani and Jewasikiewtz [3] regarded South Africa as a model for African economic development. In the meantime, they have seen urban poverty as the most serious problem facing the post-apartheid government. Thus many individuals and households in South African cities have increasingly started adopting multiple and diverse strategies to cope with the challenge of poverty by using the informal sector as a solution to the challenge. Informal waste recycling has helped many poor urban dwellers to earn income and make a living (Sentime [4] and Samson [5]). Sentime [4] reports that an estimated total number of $48 \%$ of the urban residents in the city of Johannesburg are now in the industry of informal solid waste recycling which has become the main source of their income generation and livelihood strategy.

In the light of the aforementioned, it appears that most studies focused on solid waste management and informal waste recycling in an urban context, few of these studies have examined and analysed the importance of incorporating informal solid waste pickers in urban development and planning policy. Furthermore, informal solid waste management has been documented as an activity that is not fully recognised in the urban policy planning and development strategies in the countries of the Sub-Saharan Africa in general and South Africa in particular. However, including waste pickers in urban development and planning policy should form the basis that could enable changes in the promotion of green jobs and environmental sustainability in an urban context. In view of these observations, the purpose of this paper is to investigate the barriers that hinder the integration of the informal waste sector in an inclusive waste management system and mechanism. The paper also proposes an approach for a sustainable solution to informal waste management in the city of Johannesburg. 


\section{Solid waste management in Sub-Saharan African countries}

Many cities of the Sub-Saharan African countries experience high rate of population growth stemmed from the process of migration, urbanisation, industrialisation and modernisation (Simelane and Mohee [6]). Increase in population has an impact on solid waste production in cities, which further shaped the existing solid waste management systems and cause challenges to the already desperate urban authorities. A study carried out in the East African region illustrates the financial dilemma concerning to the management of solid waste (Liyala [7]). In Uganda, Tanzania and Kenya, for instance, the problems associated with waste management is categorised as: fiscal (lack of funding), socio-cultural (lack of awareness, education and attitude) and technical (capacity, wrong equipment, inadequate equipment) (Henry et al. [8]). Most of the urban residents in the cities of the Sub-Saharan Africa perceive waste as a problem that affects human health and environmental well-being, and that solid waste management should be the responsibility of government. Tukahirwa and Lukooya [9] are of the view that improving funding and developing technical capacity should form the basis and mechanisms that could address the waste management challenges faced by the urban managers in the cities of SubSaharan Africa. This situation also requires the involvement of stakeholders at all levels and in all sectors to have a consensus and create an integrated and sustainable approach to solid waste management.

The collection, transportation, disposal and treatment of waste have proved to be a challenge faced by the municipal authorities of the developing world (Gumbo and Simelane [10]). Of greatest concern is both the lack and high cost of modern technology that efficiently and effectively converts waste to energy. Some of the projects that have already been implemented on the African cities, for example, suffer with critical shortages of experienced and well-trained personnel (El-Khattam et al. [11]). It must also be noticed that most of African countries lack appropriate policies and legislations that could support investment in waste recycling. Where these policies and legislations exist, they have proved to be inconsistent in their application. For example, in the eThekwini municipality in South Africa: the appropriate technologies, particularly the engines to convert the gas to electricity, have proved to be expensive. This situation has created a scenario by which the municipality has to borrow money from international sources (Chimuka and Ogola [12]). It would therefore not be an exaggeration to argue that the failure in waste management lies in the fact that African countries lack the know-how and appropriate technology susceptible to handle the increasing quantities of waste generated in the cities (Mudhoo et al. [13]). This situation is the result of the weak economies and poor financial management and administrative capacity that are often observed in the cities of the developing world (Muniafu and Otiato [14]), which consequently affects the ability of the local authorities to enforce environmental legislation and policies.

Despite the many strides South Africa has made in the management of its municipal solid waste, but there still some challenges to overcome. In addition to the solid waste management challenges, Chimuka and Ogola [12] are of the view 
that in some cases, the lack of skilled staff and funds, apathy at managerial level, corruption and mismanagement in municipalities are all contributing against the creation of a sustainable approach to urban solid waste management. Furthermore, increased in population in cities together with rural-urban migration have further worsened and complicated the problem of solid waste management. The rural-urban migration has resulted in the expansion of informal settlement in urban areas and this is the case for Johannesburg too, where informal settlements have proved to be expanding exponentially (Samson [5]). Some of the challenges are readily appreciated when looking at the entire current urban municipal solid waste management system, and comparing it with that of other countries. What it boils down to is that it is not enough simply to have good legislation and to spend time thinking of appropriate technologies and/or methods to manage municipal solid waste. The other factors are also important, such as careful planning awareness by the local municipalities on the entire topic of urban municipal solid waste management practices. In order for these practices to be properly implemented and become successful, the role of communities also needs to be taken into consideration.

\section{Methodology}

The data on which this paper is based was collected in the city of Johannesburg during the month of September to November 2015. Because of the nature of the study, it was purposely decided to select seventy-three (73) waste pickers who were willing to participate in the study. The remaining participants were selected through snowballing sampling method: 3 directors from buy-back centres were selected and included in the survey (Maningi scrap metals, Far-point recycling and Remade recycling), key informants from (Environment and Infrastructure Services Department, Department of Agriculture and Rural Development (Waste Management), Pikitup, Geza Jozi and Bathopele co-operative). Figure 1 portrays the spatial location of buy-back centres in Johannesburg City and Suburban.

Participant research observations and the snowballing sampling method were conducted during the investigation. This technique of data collection was particularly important because some of the research buy-back centres sites do not experience a constant presence of the waste pickers on a regular basis. Thus, using key informants, research participants who work in the municipality and organisations were identified and visited. In addition, ground-truthing exercises, semi-structured interviews, participant observations, and key informants were used as the main data collection instruments. The questions that were asked solicited for information on the barriers to an inclusive waste management system, most recycled materials, challenges encountered by waste pickers and contributions of street waste pickers on solid waste management. Other questions sought to obtain information on the possible ways or an approach for a sustainable solution to informal waste recycling in the city of Johannesburg. 


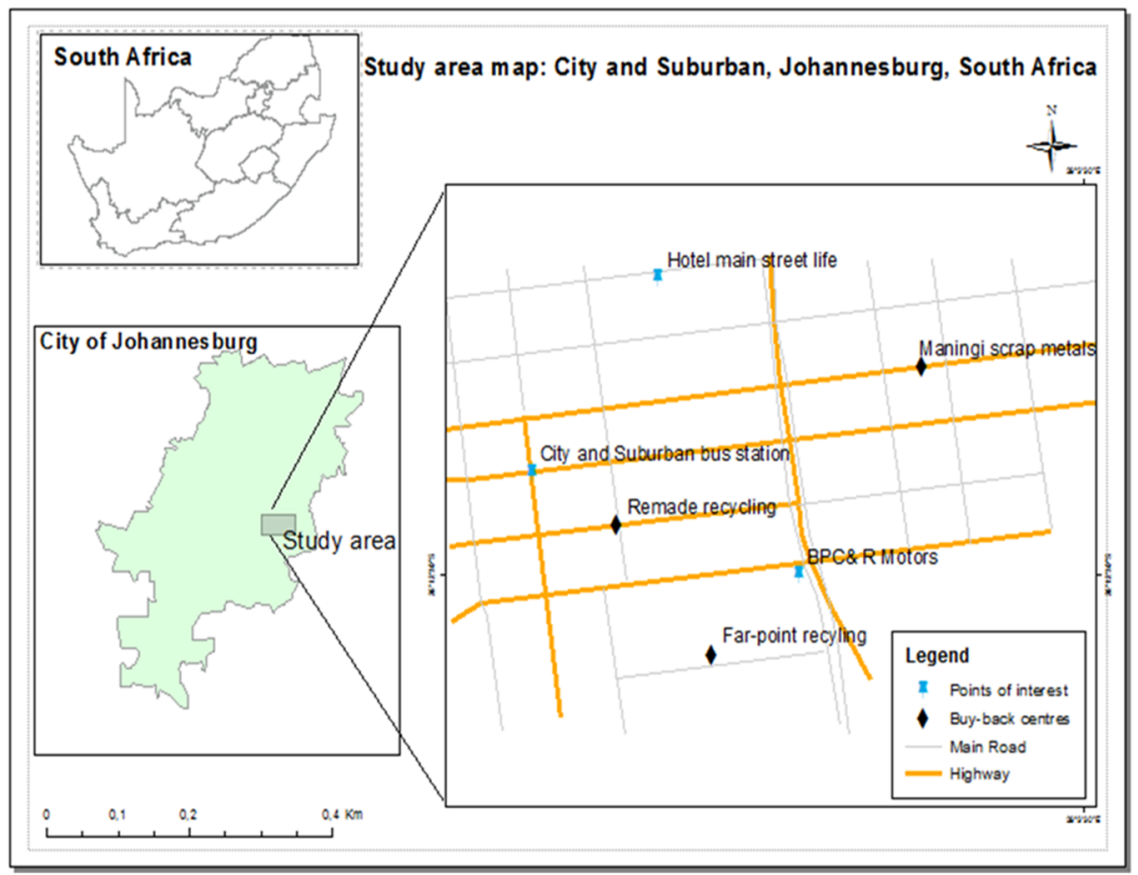

Figure 1: Johannesburg City and Suburban, South Africa.

\section{Results}

Four factors were identified as barriers to an inclusive solid waste management in the city of Johannesburg: First, there is lack of cooperation between waste pickers and municipal authorities. It was mentioned by a research participant from the city of Johannesburg that there is lack of coordination between waste pickers and the authorities in charge of waste management. The lack of effective coordination and management systems has led to conditions that are harsh on waste pickers. He added that:

"It is very difficult to get funds, resources or to break through the municipal channels. What we try to do now is to ask for trolleys in companies. Meanwhile, we are not organised yet companies want us to first register with the city of Johannesburg."

This observation suggests that municipal waste authorities are not informed about informal waste recycling. They do not have an idea of the real issues that waste pickers come across on the ground. Through direct involvement with waste pickers, municipalities can better understand the real issues pertaining informal waste recycling.

Specific push factors (unemployment and orphanage) force individuals to migrate from rural areas to the city of Johannesburg. Most waste pickers are attracted by pull factors (job opportunities and better living standards) which 
they believe will make life easier once off from the rural areas to the city of Johannesburg (Figure 2). Key informants, director's and waste pickers highlighted that informal waste recycling is mainly exacerbated by unemployment. Informal waste recycling then tends to be an alternative source of employment and a source of livelihood.

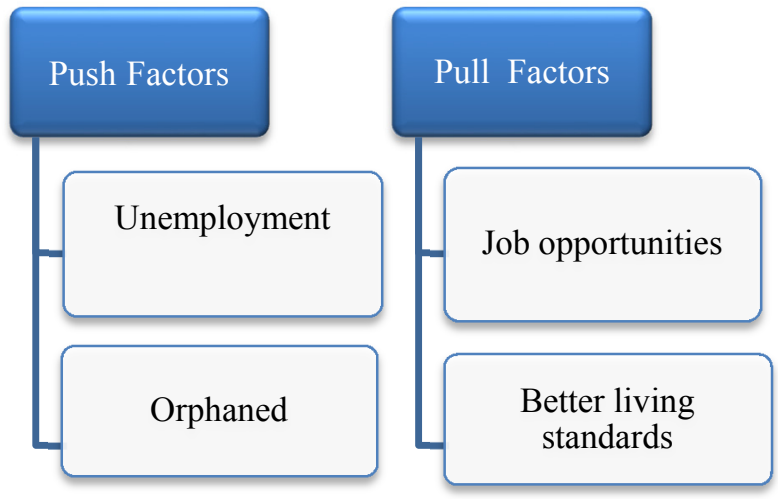

Figure 2: Push and pull factors.

Although informal waste recycling in the city of Johannesburg is not in anyway different from that obtained in other sub-Saharan African cities, its uniqueness lies in the fact that it has been exacerbated, not only by poverty and unemployment but by increased level of institutional failures. Sentime [15] stated that the legislative framework does not recognise informal waste recycling in South Africa. Necessary regulatory framework governing informal waste recycling is not yet set-up to solve the problem of increasing solid waste generation in the city of Johannesburg.

The discussions with key informants provided that there is a lack of existing institutional framework in the city of Johannesburg through which the interests of vulnerable solid waste pickers would be protected and enhanced. This is truly because in the city of Johannesburg, there is lack of transparency among institutions and inadequate accountability in the entire waste management system. In line with the above observations, research participants acknowledged that municipal authority are not working fairly with them, they only make promises which results into low government willingness to implement proper waste management strategies, infrastructure and regulations. Thus the solid waste management challenge in South Africa and the city of Johannesburg in general, has not been a result of political instability and lack of resources, but has been largely embedded in structural challenges such as the absence of an institutional and policy framework as well as unending corruption among institutions combined together with lack of effective coordination and management systems in the various waste management sectors.

However, in the face of institutional and policy challenges in solid waste management, the informal sector, through activities such as informal waste 
recycling is increasingly playing a critical role in the management of waste in the city of Johannesburg. Figure 3, for example, is an illustration of how informal waste recycling has become part of the urban landscape and form of employment.

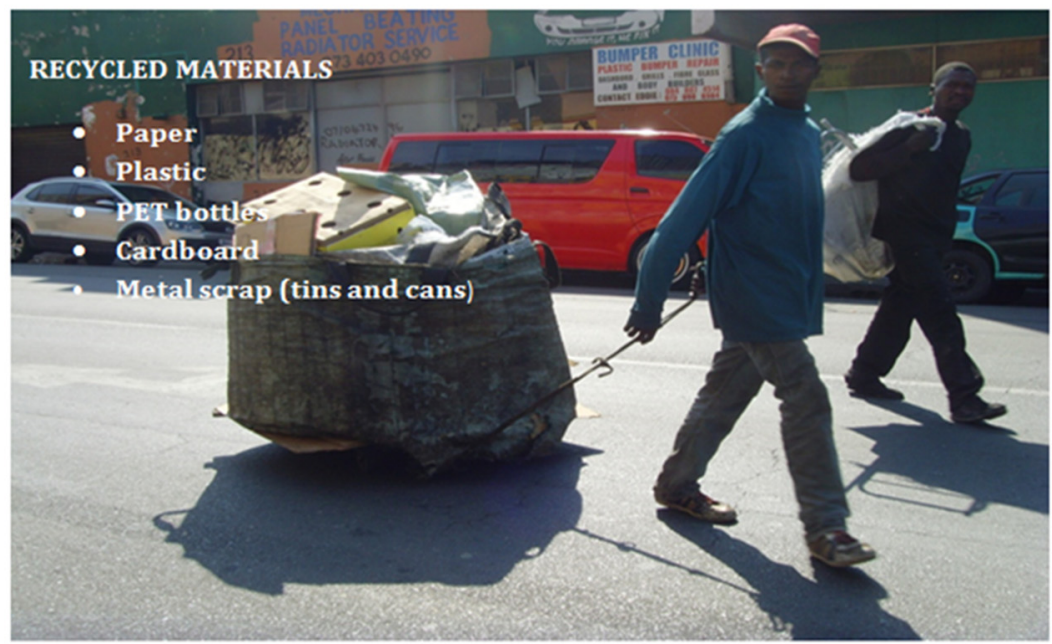

Figure 3: Street pickers in the city of Johannesburg.

The majority of the solid waste pickers are poor and less privileged urban dwellers that make a living from collecting and recycling solid wastes. Table 1 for example, shows the demographic aspects of the research participants in the city of Johannesburg.

Table 1: Demographic characteristics of research participants.

\begin{tabular}{|l|l|c|c|}
\hline Variable & Category & No of respondents & $\%$ \\
\hline \multirow{3}{*}{ Gender } & & & \\
& Male & 69 & 95 \\
\hline Age Range & Female & 4 & 5 \\
& $15-25$ & 13 & 18 \\
& $26-35$ & 44 & 60 \\
& $36-45$ & 11 & 15 \\
& $46-55$ & 4 & 6 \\
\hline \multirow{3}{*}{ Total } & $56-65$ & 1 & 1 \\
\hline
\end{tabular}

Information presented in table 1 revealed that the majority of street waste pickers are men representing $95 \%$ of them and that a recent phenomenon has been the presence of women involved in this industry and they represent 5\%. A further scrutiny of table 1 reveals that $60 \%$ of all waste pickers were aged 
between 26 and 35; 18\% were aged between 15 and 25 and $15 \%$ were between 36 and 45 years. These figures suggest that informal waste recycling in the city of Johannesburg is an activity mainly dominated by young people.

Second, repressive policy and social acceptance: another difficulty towards the recognition of waste pickers is repressive policy and social acceptance. Waste pickers stated that society and authorities view their activities as backwards and a social problem that needs to be removed. The obvious challenge is that of neglect, with cases of removal of collection makeshifts and stored recyclable waste by metro police. Another research participant, for example commented that:

"Every day, taxi drivers beat us and call us names, saying we are blocking the road. They hit us on purpose, others they ran over our trolleys. I decide not to entertain them because at the end of the day we are all trying to make ends meet. It is true others understand us but most of them insult us."

Because of their lack of recognition, waste pickers have never featured as significant role players in the waste management system since they are unwelcome strangers. This research revealed therefore, that the most outstanding social problems that waste pickers face is harassment more especially by Johannesburg Metro Police, taxi drivers and urban residents (Table 2). It is presented in the table that $37 \%$ of respondents interviewed mentioned that harassment is a social problem that they encounter in the city of Johannesburg. Almost $29 \%$ of the research participants revealed that they experience a problem with mistreatment by drivers on the roads and heavy traffic. Furthermore, it is also revealed that $22 \%$ of the respondents mentioned that they have a problem with the smell from dustbins as they do not have proper protective equipment to use when claiming recyclable materials. They mentioned that since waste is not separated at source, they have to first take out recyclable waste from the dustbins.

Table 2: $\quad$ Social challenges encountered by waste pickers.

\begin{tabular}{|l|l|c|c|}
\hline $\begin{array}{c}\text { Challenges/ } \\
\text { Problems }\end{array}$ & \multicolumn{1}{|c|}{ Frequency } & $\begin{array}{c}\text { No. of } \\
\text { respondents }\end{array}$ & \% \\
\hline Physical injury & IIIII III & 9 & 12 \\
\hline Sickness & IIIII IIIII IIIII I & 16 & 22 \\
\hline Harassment & IIIII IIIII IIIII IIIII IIIII II & 27 & 37 \\
\hline Heavy traffic & IIIII IIIII IIIII IIIII I & 21 & 29 \\
\hline Total & & $\mathbf{7 3}$ & $\mathbf{1 0 0}$ \\
\hline
\end{tabular}

According to Simatele and Etambakonga [16] the negative behaviour towards waste pickers could be argued as being motivated by a lack of knowledge on the part of urban managers in terms of the contribution of informal solid waste recycling to the entire solid waste management system. Therefore, a positive change in the public's perception on informal waste recycling is an important 
step to secure a healthy working environment for waste pickers. In view of the above sentiments, it would not be an exaggeration to argue that in the city of Johannesburg, the major limitation to social acceptance of the informal waste sector is that they have not been integrated into an inclusive waste management system.

Moreover, most street waste pickers complained that there is no separation at source, and therefore papers, plastics, bottles and other wastes are not separated. Also due to the non-existence of resource recovery programmes, residents do not see the need to separate and recycle their waste. Municipalities need to understand that a more effective way to reduce waste is to deal with it at source through recycling. Supporting this assertion, Simelane and Mohee [6] are of the view that waste separation at source strongly depends on the level of education of citizens, government commitment and financial incentives and proper infrastructure. Appropriate education of citizens and awareness can change public and waste picker's perceptions in the city of Johannesburg. Bottom up inclusive activities such as workshops, community meetings, radio, print and television programmes and awareness campaigns, are an effective tool to disseminate information and enhance the participation of various sectors of the population.

Third, illegal migrants and lack of valid citizenship documents: another drawbacks mentioned by directors and key informants is that it is hard for authorities to recognise informal waste pickers who reclaim recyclable waste in the city of Johannesburg because most waste pickers are originally not from South Africa. Key informants mentioned that:

"We have approximately 40\% of waste pickers who are not from South Africa. Again those who are South Africans do not have citizenship documents."

Likewise, interviews conducted with waste pickers pointed out that many of the waste pickers do not have identity cards or at least passports. Key informants therefore, pointed out that they can only consider waste pickers who are originally from South Africa, of which a majority of them are not South Africans. Another official revealed that most waste pickers are crime bearing individuals hence they do not have identity documents. He mentioned that "So even if government can try to recognise waste pickers, it will not help because the system will pick up individuals who once committed crime."

Fourth, lack of supporting evidence: Authorities pointed out that amongst challenges, waste pickers do not have a database. They see them in the streets of Johannesburg but their activities are not documented and organised. Key informants mentioned that:

"In this essence, government cannot give opportunities to individuals." Officials further mentioned that "It is thus very hard to help people without knowing their contributions in waste management. In general, we do not know their numbers, their working networks, and their working stations. "

Literature states that given the lack of data on waste activities, and indeed the difficulty in measuring many important aspects, makes it difficult to tackle some important players in waste management. From this angle, it can be argued that 
without commitment and dedication by municipal authorities on informal waste recycling; waste pickers activities will have no database.

\section{Discussion}

A database of waste pickers can be developed and updated on regular basis in the city of Johannesburg. The registration process can be undertaken through the assistance of waste committees and buy-back centres. Through this process, the municipal department can be able to gather information on waste pickers operating within the city. This information can give the department an indication of where reclamation activity influx is at and the role that waste pickers play in the waste management value chain. This process can develop a platform of communication where the city authorities can engage on waste management challenges with waste pickers through their committees and association. Environmental departments can also work with the Department of Economic Development and other NGOs to assist waste pickers to form cooperatives and collaboration. Cooperatives can assist in sustaining the project and improve the lives of the waste pickers by creating opportunities for waste pickers to actively participate in formal waste management activities.

Thus figure 4 presents a model of institutional arrangement for informal solid waste pickers' inclusion and recognition in urban solid waste management planning policy and developmental strategies. This model explicates how the urban authorities can enable and register the waste pickers operation in urban

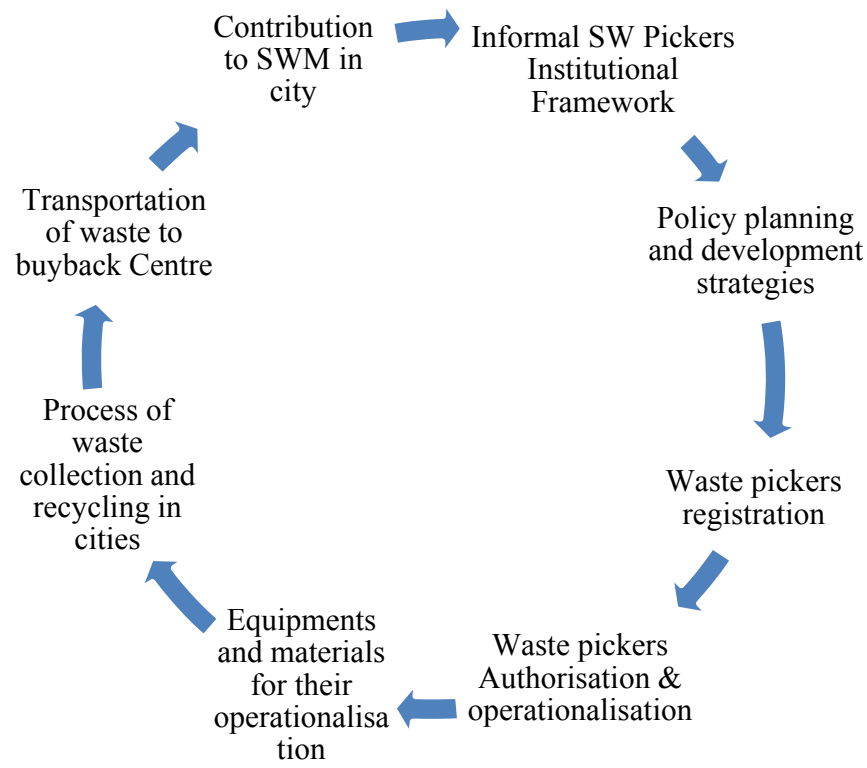

Figure 4: Institutional arrangement for informal solid waste picker's recognition. 
development. These waste pickers, once, formally registered and authorised to operate, they have to be provided with materials and equipment susceptible to execute their tasks by collecting recyclable wastes in the cities and transport them to buy-back centres. This operation, not only help the waste pickers earn an income but also it contributes to urban environmental solid waste management and sustainability.

In view of the above observations, the municipal waste department can conduct a needs analysis workshop. The workshop can be used as a platform to understand issues that waste pickers encounter and for the city to be able to prioritize their needs. The workshop can be for the relevant stakeholders to identify the role that they can play and commit themselves to the empowerment of waste pickers. The stakeholders can include: Industries, National/ Provincial Departments and City of Johannesburg departments.

Personal Protective Equipment (PPEs) and trolley for waste pickers can be procured by the Department of Environmental Affairs, Pikitup, Department of Environment and Infrastructure Services, Department of Economic Development and buy-back centres. Protective clothing can consist of reflector vests which are visibly to motorist during the day and night, as waste pickers use roads. Sustainable boots which can be comfortable in their everyday walking distance. Protective clothing can include dust masks and gloves; this can protect them when they are reclaiming not to inhale dangerous or hazardous substances which might be found in the waste that is being reclaimed.

Training can be conducted in collaboration with the afore-mentioned environmental departments. The training can focus on business skills, recycling and the city of Johannesburg by-law requirements and compliance. The training can give an opportunity to the waste pickers to understand their work and how does it fits in the waste management value chain of the city of Johannesburg. When the project is rolled out, the city can further retrain waste pickers in order to reskill them if there are new developments in the recycling industry. A pilot project can be launched in the city of Johannesburg and thereafter be rolled out to other parts of the city.

\section{Conclusion}

The main objective of this paper was to investigate the barriers that hinder the integration of the informal waste sector in an inclusive waste management system. The paper also proposed an approach for a sustainable solution to informal waste management in the city of Johannesburg. It has been suggested and argued in this paper that informal waste recycling in the city of Johannesburg is an activity dominated by men, and in some cases women. It has been revealed that, waste pickers are vulnerable more especially to harassment by metro police, urban residents and motorist. However, it has been argued that government need to acknowledge and recognise waste pickers activities in the urban policy planning and development strategies in South Africa. This situation owes much to the barriers to inclusive waste management: lack of cooperation, social acceptance, lack of valid citizenship documents and lack of supporting 
evidence. In view of this observation, municipalities can empower waste pickers through an institutional arrangement for informal waste sector inclusion and recognition in urban waste management planning policy and development. Urban authorities can conduct workshops where they can register, train, discuss issues and provide protective equipment for waste pickers through cooperatives. Integration of waste pickers will therefore ensure increased community commitment and participation, both in terms of waste recycling and management.

\section{References}

[1] SAIRR, www.southafrica.info/news/urbanisation-240113.htm

[2] Kubanza, N.S. \& Simatele, D., Social and environmental injustices in solid waste management in sub-Saharan Africa: a study of Kinshasa, the Democratic Republic of Congo, Local Environment. The International Journal of Justice and Sustainability, 2015.

[3] Karani, P. \& Jewasikiewitz, S.M., Waste management and sustainable development in South Africa. Environment, Development and Sustainability, 9(2), pp. 163-85, 2007.

[4] Sentime, K., Profiling solid waste pickers: a case study of BraamfonteinGreater Johannesburg. Africanus, 41 (2), pp. 96-111, 2011.

[5] Samson, M., Wasted Citizenship? The role of reclaimers in South Africa municipal waste management. University of the Witwatersrand, 2008.

[6] Simelane, T. \& Mohee, R., (eds). Future Directions of Municipal Solid Waste Management in Africa, Pretoria: Africa Institute of South Africa, 2015.

[7] Liyala, C.M., Modernizing solid waste management at municipal: institutional arrangements in municipalities of East Africa. Wageningen University, 2011.

[8] Henry, R.K., Yongsheng, Z. \& Jun, D., Municipal solid waste management challenges in developing countries: Kenyan case study. Waste Management, 26, pp. 92-100, 2006.

[9] Tukahirwa, J.T. \& Lukooya, N.B., The role of policy and institutional reforms in enhancing technical efficiency of urban authorities: reference to solid waste management in Kampala City, Uganda (Chapter 8). Future Directions of Municipal Solid Waste Management in Africa, ed. T. Simelane, R Mohee: Africa Institute of South Africa, South Africa, pp.136-154, 2015.

[10] Gumbo, T. \& Simelane, T., Innovations in municipal solid waste management: experiences from eThekwini Municipality, South Africa (Chapter 11). Future Directions of Municipal Solid Waste Management in Africa, ed. T. Simelane, R Mohee: Africa Institute of South Africa, South Africa, pp. 202-217, 2015.

[11] El-Khattam, W., Hussein, S. \& Abdel-Rahman, M., State of energy infrastructure in Africa: How much investment is needed to migrate to renewable energy? (Chapter 3). Energy transition in Africa, ed. T. 
Simelane, M. Abdel-Rahman: Pretoria: Africa Institute of South Africa, pp. 55-89, 2011.

[12] Chimuka, L. \& Ogola, J., Leading the way: directions of municipal solid waste management in South Africa (Chapter 7). Future Directions of Municipal Solid Waste Management in Africa, ed. T. Simelane, R. Mohee: Africa Institute of South Africa, South Africa, pp. 176-199, 2015.

[13] Mudhoo, A., Mohee, R. \& Simelane, T., Future Directions of Municipal Solid Waste Management in Africa, Pretoria: Africa Institute of South Africa, 2015.

[14] Muniafu, M. \& Otiato, E., Solid waste management in Nairobi, Kenya. A case for emerging economies. The Journal of Language, Technology and Entrepreneurship in Africa, 2 (1), pp. 342-350, 2010.

[15] Sentime, K., The impact of legislative framework governing waste management and collection in South Africa. African Geographic Review, 33 (1), pp. 81-93, 2014.

[16] Simatele, D. \& Etambakonga, C.L., Scavenging for solid waste in Kinshasa: A livelihood strategy for urban poor in the Democratic Republic of Congo. Habitat International, 49, pp. 266-274, 2015. 